\title{
Analisis dan Perancangan Domain Specific Language untuk Data Generator pada Relational Database
}

\author{
VANIA NATALI ${ }^{1}$, PASCAL ALFADIAN ${ }^{2}$ \\ ${ }^{1}$ Universitas Katolik Parahyangan, Bandung, Indonesia \\ 2 Universitas Katolik Parahyangan, Bandung, Indonesia \\ Email: vania.natali@unpar.ac.id
}

\begin{abstract}
ABSTRAK
Data dummy seringkali diperlukan dalam proses belajar basis data, pengujian perangkat lunak, pengujian performansi basis data, dan lain-lain. Proses pembuatan data dummy seringkali memerlukan waktu yang tidak sedikit. Penelitian ini bertujuan untuk merancang Domain Specific Language (DSL) yang dapat digunakan dalam kakas generator data. DSL yang dikembangkan didasarkan pada Data Definition Language (DDL) dari basis data relasional dengan spesifikasi pada sintaks create table. Kontribusi penelitian ini adalah DSL dan grammar yang dapat digunakan untuk melakukan proses parsing $D D L$ yang akan menjadi bagian dari kakas generator data.
\end{abstract}

Kata kunci: data dummy, domain specific language, generator data.

\begin{abstract}
Dummy data is often required in database learning process, software testing, database performance testing, etc. The process of making dummy data often takes a long time. This research aims to design Domain Specific Language (DSL) that can be used in a data generator software. DSL has been developed based on Data Definition Language (DDL) of relational database with specification in create table $D D L$ command. The contribution of the research is a DSL and a grammar for parsing $D D L$ that will be a part of data generator software.
\end{abstract}

Keywords: data generator, domain specific language, dummy data. 


\section{PENDAHULUAN}

Dalam bidang basis data, data dummy dapat digunakan sebagai sarana pembelajaran, pengujian performansi basis data, pengujian perangkat lunak, dan lain-lain sebagainya. Jumlah data dummy yang diperlukan pada umumnya cukup besar. Saat ini, telah ada beberapa aplikasi yang dapat digunakan sebagai data generator. Kemampuan yang difasilitasi oleh masing-masing data generator tentunya berbeda. Sebagian besar data generator freeware tidak memfasilitasi pembuatan data dummy yang memperhatikan constraint basis data, misalnya foreign key.

Pada penelitian ini, dilakukan analisis dan perancangan Domain Specific Language (DSL) dan grammar yang dapat digunakan dalam kakas data generator. DSL adalah sebuah bahasa pemrograman komputer yang diekspresikan secara terbatas dan fokus pada domain tertentu (Fowler \& Parsons, 2010). DSL yang dibuat akan didasarkan pada input berupa script Data Definition Language (DDL). Dengan kebebasan mendefinisikan sebuah bahasa pemrograman baru, diharapkan dengan DSL tersebut, dapat dibuat sebuah perangkat lunak data generator yang memperhatikan constraint basis data di kemudian hari. Dalam basis data relasional, constraint basis data penting untuk diperhatikan karena jika diabaikan, data yang dihasilkan akan tidak valid dan tidak dapat memenuhi syarat sebagai data untuk pembelajaran atau pengujian.

Pada bagian berikut ini akan dibahas mengenai beberapa penelitian terkait.

Dalam penelitian (Feuto, Cardey, \& Gree, 2013), (Marinos \& Krause, 2009), dan (Moschoyiannis, Marinos, \& Krause, 2010), peneliti memanfaatkan DSL untuk menyatakan aturan bisnis yang dituliskan dengan spesifikasi Semantic of Business Vocabulary and Business Rules (SBVR). Penulis menentukan beberapa kategori aturan bisnis, kemudian menentukan DSL untuk aturan-aturan bisnis tersebut. DSL tersebut digunakan dalam pembangunan prototype perangkat lunak untuk menuliskan aturan bisnis dalam SBVR. DSL yang digunakan dalam penelitian (Feuto, Cardey, \& Gree, 2013) tersebut tertera pada Gambar 1.

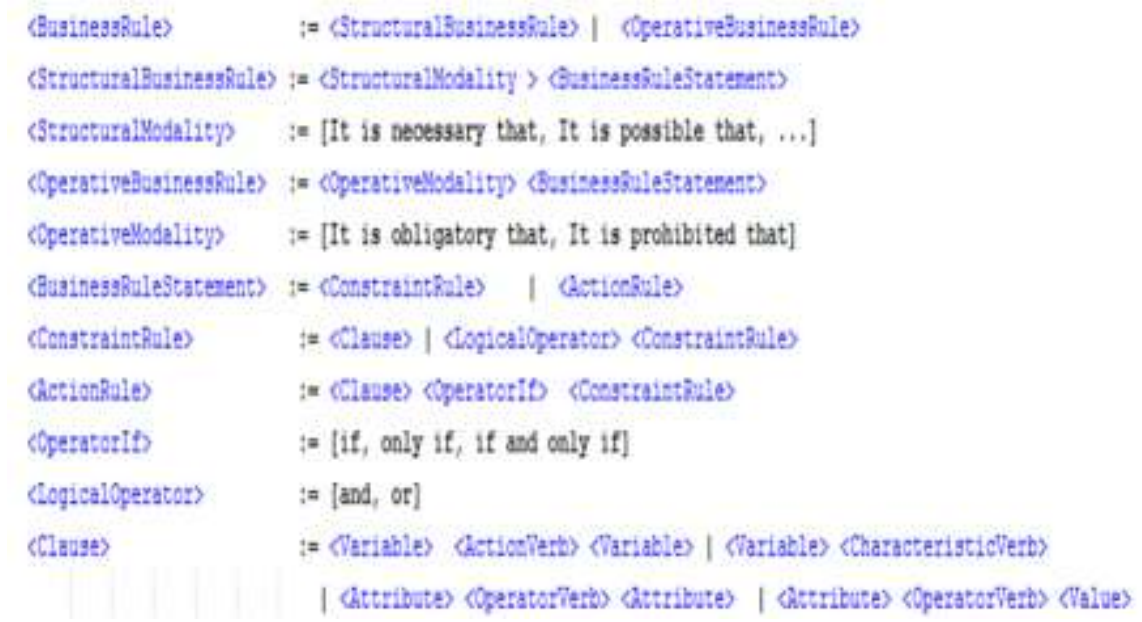

\section{Gambar 1. DSL untuk Aturan Bisnis (Feuto, Cardey, \& Gree, 2013)}

Dalam (Natali \& Liem, 2015), peneliti mengembangkan DSL untuk aturan bisnis berbahasa Indonesia. DSL tersebut digunakan untuk membangkitkan query SQL secara otomatis. Query tersebut digunakan untuk memeriksa ketaatan data terhadap aturan bisnis. 
Salah satu contoh pola kalimat yang digunakan dalam DSL pada (Natali \& Liem, 2015) tertera pada Gambar 2.

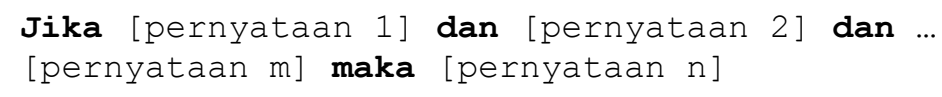

\section{Gambar 2. Contoh DSL untuk Aturan Bisnis dalam Bahasa Indonesia (Natali \& Liem, 2015)}

Agar kalimat yang telah ditulis dalam pola Gambar 2 dapat dikenali oleh komputer, maka diperlukan grammaratau pola bahasa. Cuplikan grammaryang digunakan pada (Natali \& Liem, 2015) diberikan pada Gambar 3

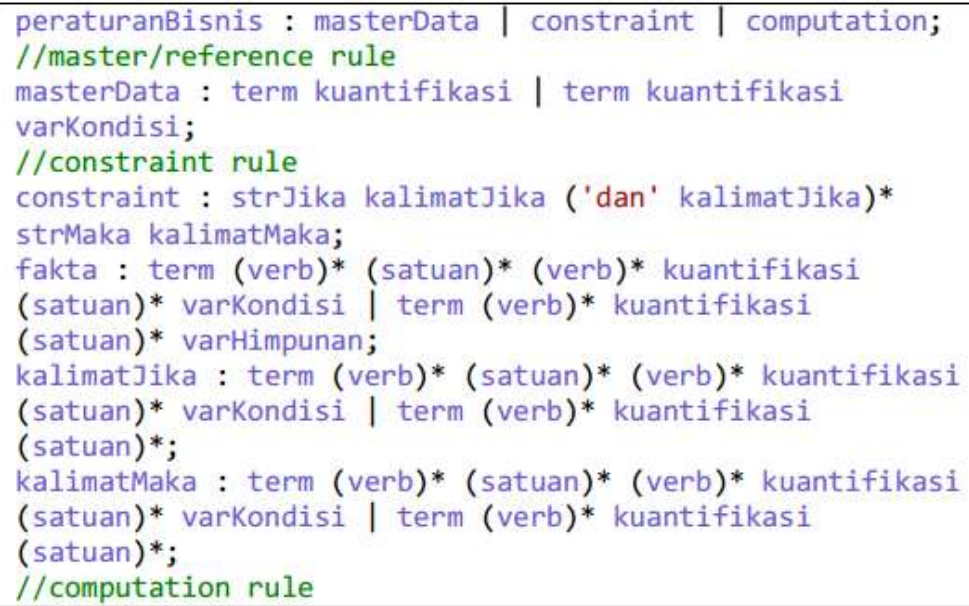

Gambar 3. Grammar untuk Aturan Bisnis dalam Bahasa Indonesia (Natali \& Liem, 2015)

Salah satu template query SQL yang digunakan dapat tertera pada Gambar 4.

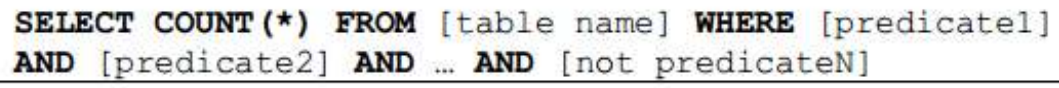

\section{Gambar 4. Template Query SQL (Natali \& Liem, 2015)}

Contoh query yang dihasilkan pada penelitian (Natali \& Liem, 2015) dapat dilihat pada Gambar 5.

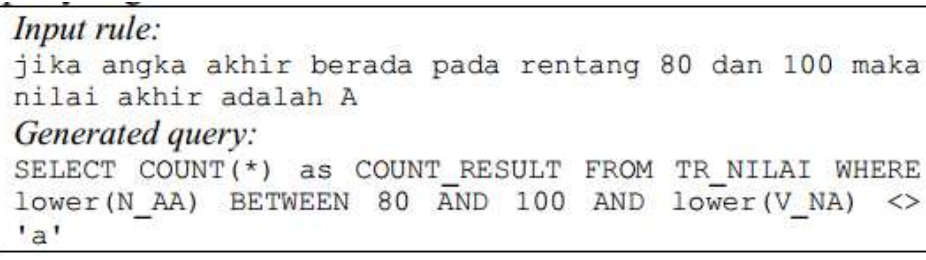

Gambar 5. Contoh Query SQL untuk Pemeriksaan Data (Natali \& Liem, 2015) 


\section{METODOLOGI}

\subsection{Domain Specific Language}

Definisi dari Domain Specific Language (DSL) adalah sebuah bahasa pemrograman komputer yang diekspresikan dengan cara tertentu/terbatas dan berfokus pada domain tertentu (Fowler \& Parsons, 2010). DSL dapat digunakan dalam domain tertentu, dimana format ekspresi bahasa dalam domain tersebut dapat diformulasikan dengan struktur tertentu. Implementasi DSL perlu melalui beberapa tahap, yaitu sebagaimana tertera pada Gambar 6.
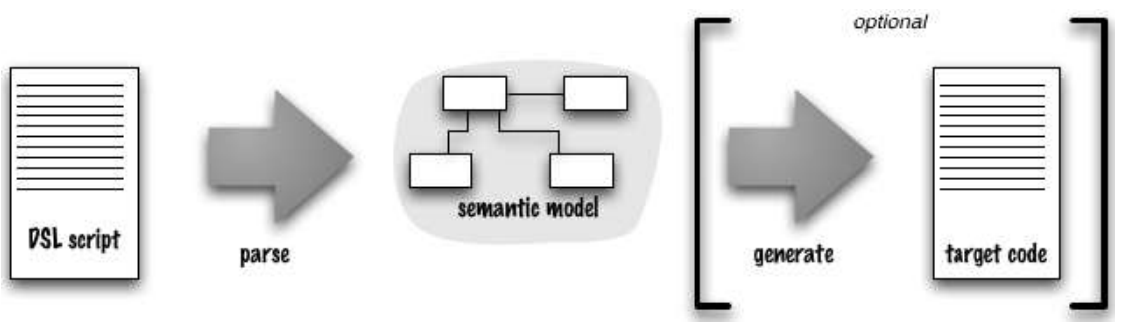

\section{Gambar 6. Arsitektur Pemrosesan DSL (Fowler \& Parsons, 2010)}

Proses pertama yang perlu dilakukan adalah perancangan DSL script. Proses perancangan DSL script ini memerlukan penangkapan pola dari domain terkait. Pola tersebut dapat ditangkap jika ekspresi pada domain tersebut terbatas pada formula tertentu. Proses selanjutnya dapat dilakukan dengan bantuan aplikasi yang disediakan untuk memproses DSL, misalnya Another Tool for Language Recognition (ANTLR).

\subsection{ANTLR}

ANTLR adalah generator yang bermanfaat untuk membaca, memproses, dan mengeksekusi, atau menerjemahkan teks yang terstruktur (structured text). Bahasa (language) yang dimaksud adalah sekumpulan kalimat yang valid. Kalimat terbentuk dari frasa-frasa. Sebuah frasa tersusun dari sub-frasa dan simbol-simbol vocabulary. ANTLR bertindak sebagai parser atau syntax analyzer, yaitu program yang berguna untuk mengenali bahasa.

Pada bagian ini, akan diberikan sekilas ulasan mengenai cara kerja ANTLR. Jika diberikan grammar sebagai berikut:

assign : ID '=' expr ';';

dan input kalimat

$\mathrm{sp}=100$

maka akan dihasilkan parse tree seperti yang diberikan pada Gambar 7.

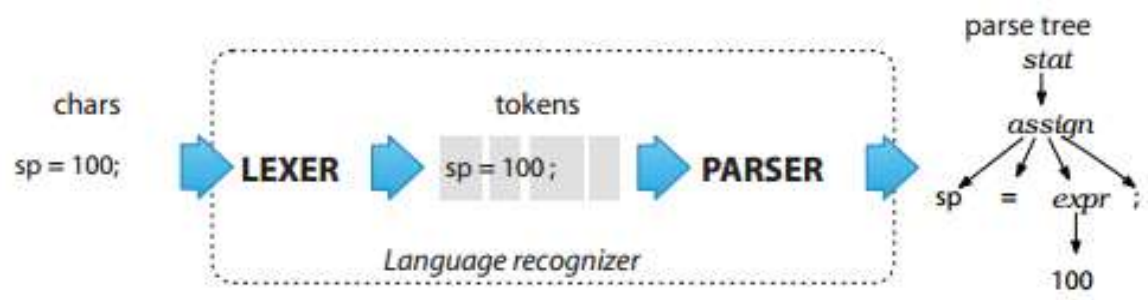

Gambar 7. Proses Pengenalan Bahasa (Parr, 2012)

\subsection{Database Language}

Secara umum, database language dapat dikategorikan menjadi dua, yaitu Data Manipulation Language (DML) dan Data Definition Language (DDL). DML memungkinkan pengguna untuk 
mengakses atau memanipulasi data. DDL digunakan untuk menspesifikasikan skema basis data.

Salah satu bagian dari DDL adalah create table, yang dapat digunakan untuk membuat tabel pada basis data. Skema dasar create table dapat dilihat pada Gambar 8.

$$
\begin{aligned}
& \text { create table } r \\
& \left(A_{1} D_{1},\right. \\
& A_{2} D_{2}, \\
& \cdots \\
& A_{n} D_{n}, \\
& \left\langle\text { integrity-constraint }{ }_{1}\right\rangle, \\
& \ldots, \\
& \left.\left\langle\text { integrity-constraint }{ }_{k}\right\rangle\right) ;
\end{aligned}
$$

\section{Gambar 8. Skema Dasar DDL Create Table (Silberschatz, Korth, \& Sudarshan, 2011)}

Dalam DDL, dapat juga dituliskan database constraint, yang pada Gambar 8 dituliskan sebagai integrity-constraint. Beberapa constraint pada basis data adalah not null, foreign key, dan primary key.

Skema dasar DDL create table yang tertera pada Gambar 8, dideskripsikan dengan cara yang berbeda-beda pada masing-masing Database Management System (BDMS). Berikut ini adalah contoh DDL create table pada dua buah DBMS.

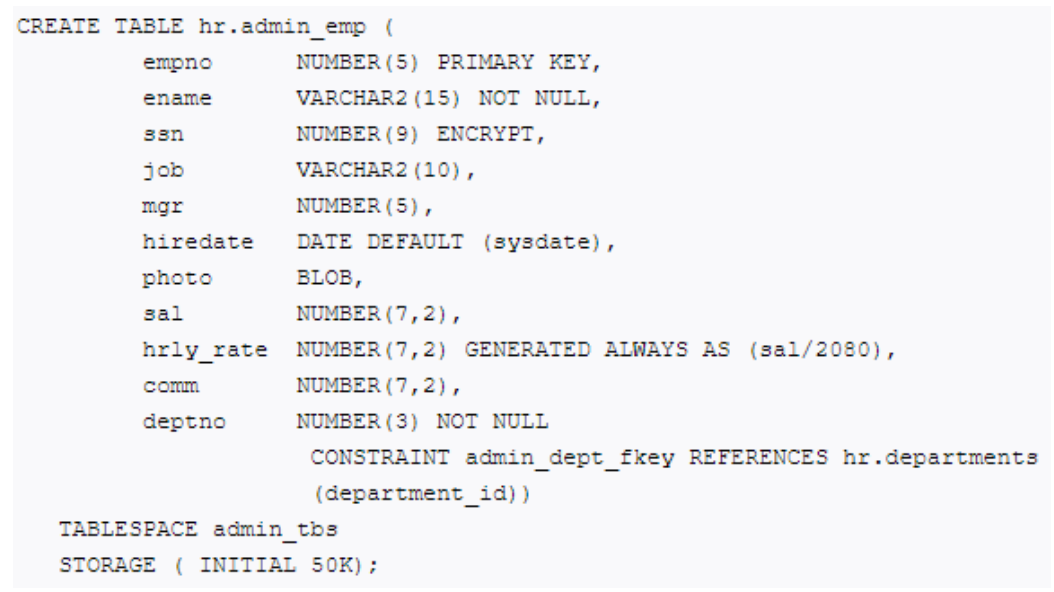

Gambar 9. Contoh DDL Create Table pada Oracle DBMS (Center, 2018)

Gambar 9 adalah contoh DDL create table pada Oracle DBMS. Sedangkan contoh DDL create table pada MySQL DBMS diberikan pada Gambar 10.

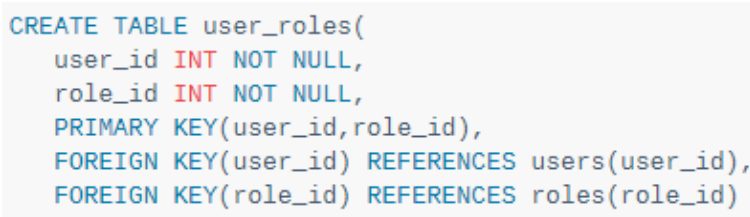

Gambar 10 Contoh DDL Create Table pada MySQL DBMS (MySQLTutorial, 2018) 
Metodologi yang digunakan pada perancangan DSL ini didasarkan pada proses yang tertera ada Gambar 6.

\section{HASIL DAN PEMBAHASAN}

Sebelum merancang DSL untuk data generator, dipelajari juga kakas data generator sejenis. Pembahasan kakas sejenis diberikan pada bagian 3.1 dan 3.2.

\subsection{Kakas Data Generator}

Saat ini telah terdapat beberapa kakas data generator, diantaranya adalah:

1. Mockaroo Realistic Data Generator.

Mockaroo menyediakan beberapa level data generator berdasarkan harga yang berbedabeda. Data yang dapat di-generate oleh pengguna yang tidak berbayar adalah 1000 baris data.

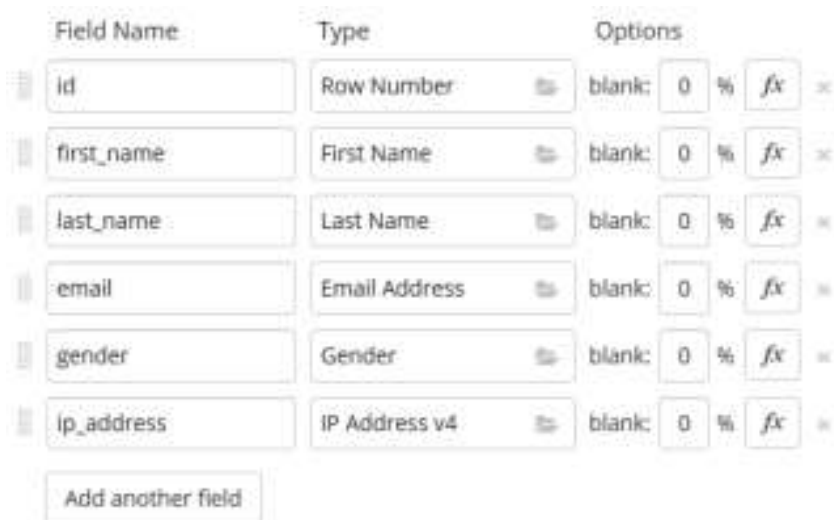

\section{Gambar 11. Tampilan Data Generator Mockaroo (LLC, 2018)}

Gambar 11 adalah tampilan dari Mockaroo. User dapat menentukan nama-nama field dan tipe data yang diperlukannya melalui user interface tersebut. Mockaroo menyediakan banyak jenis data yang dapat membantu user untuk mendapatkan data yang sesuai dengan yang diharapkannya.

2. Generatedata.com

Generatedata,com adalah kakas yang sejenis dengan Mockaroo, menyediakan fasilitas untuk membangkitkan data dummy untuk satu buah tabel. Data tersebut dapat diunduh oleh pengguna dalam berbagai jenis file, diantaranya CSV, Excel, HTML, dan SQL. Tampilan generatedata.com dapat dilihat pada Gambar 12.

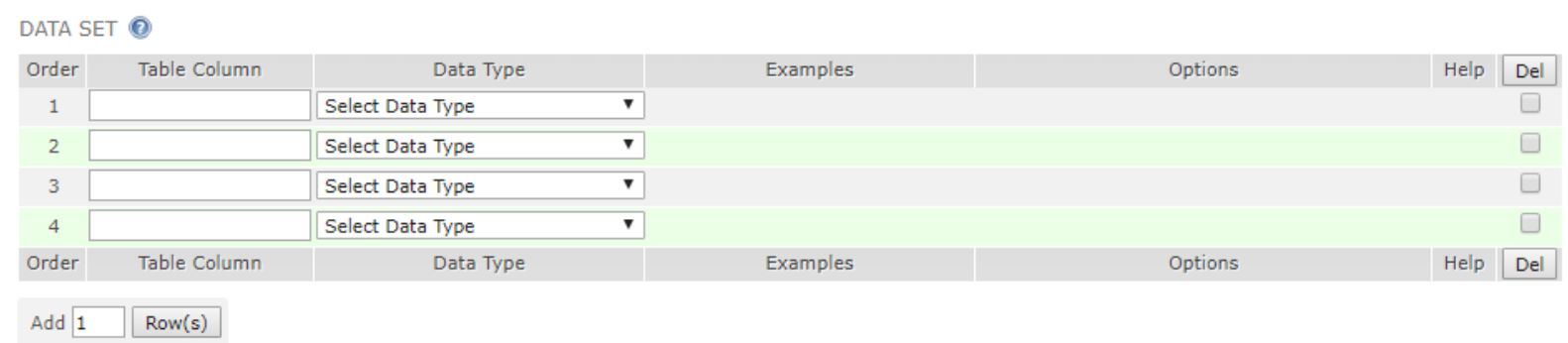

Gambar 12. Tampilan generatedata.com (Generatedata.com versi 3.2.8, 2018)

3. Data Generator from DDL-0.06 
Data Generator from DDL (Furuyama, 2018) ini men-support tiga jenis constraint basis data, yaitu primary key, unique key, dan foreign key. Jika dibandingkan dengan Mockaroo dan datagenerator.com, tipe data yang di-support oleh kakas ini lebih terbatas jenisnya. Namun pada kakas ini, pengguna tidak perlu mendefinisikan satu per satu field pada tabel yang ingin dibuatkan data dummy-nya. Kakas ini tidak menyediakan user interface khusus, melainkan user dapat menggunakan kakas ini dengan command line. Keterbatasannya saat ini adalah belum men-support composite constraints. Kakas ini terakhir dikembangkan pada tahuan 2014.

\subsection{Analisis Kakas Sejenis}

Berdasarkan beberapa kakas data generator yang tersedia, dapat disimpulkan beberapa hal yang perlu diperhatikan dalam pembuatan data generator, yaitu:

1. Kakas generator data memberikan pilihan untuk data yang umum diperlukan, misalnya nama depan, nama belakang, email, dan lain-lain.

2. Kakas generator data memberikan beberapa pilihan tipe data, misalnya number, text, tanggal, dan lain-lain.

3. Terdapat kakas generator data yang memberi peluang kepada user untuk menentukan persentase banyaknya data yang tidak mempunyai nilai ( $n u l$ ).

Berdasarkan hasil analisis, berikut ini adalah hal-hal yang perlu diperhatikan dalam pengembangan kakas data generator, namun tidak tampak dalam data generator yang hanya digunakan untuk menghasilkan populasi data untuk satu tabel:

1. Penentuan field yang menjadi primary key dalam sebuah tabel, hal ini diperlukan agar memastikan bahwa nilai untuk field ini tidak pernah null dan selalu bersifat unik.

2. Relasi antar tabel yang dibatasi oleh foreign key juga perlu diperhatikan. Constraint foreign key menjadi penting karena berpengaruh pada integritas data. Jika tabel A berelasi dengan tabel B dengan foreign key, maka data untuk field-field yang terkait pada dua buah tabel tersebut tidak bisa saling lepas.

3. Dapat diperhatikan juga constraint-constraint lain yang terkait dengan basis data, misalnya not null constraint, nilai minimum atau maksimum untuk suatu tabel, atau nilai-nilai spesifik apa saja yang boleh digunakan dalam suatu field.

\subsection{Pola DDL Create Table}

Masing-masing DBMS memiliki sintaks tersendiri untuk DDL create table walaupun tetap memiliki pola yang sama dengan pola yang tertera pada Gambar 8. Berdasarkan Gambar 8 dan implementasinya dalam DBMS MySQL, Oracle, dan SQLServer, pola DDL untuk sebuah tabel basis data diberikan pada Gambar 13 berikut ini.

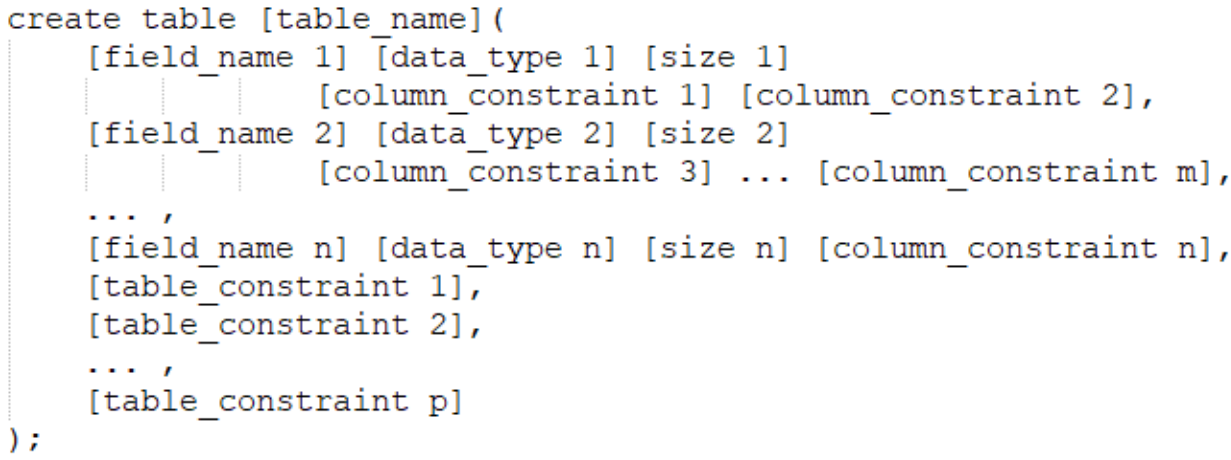

Gambar 13. Pola DSL untuk sebuah tabel basis data 
Pola umum dari penulisan column constraint pada tabel basis data dapat dilihat pada Gambar 14.

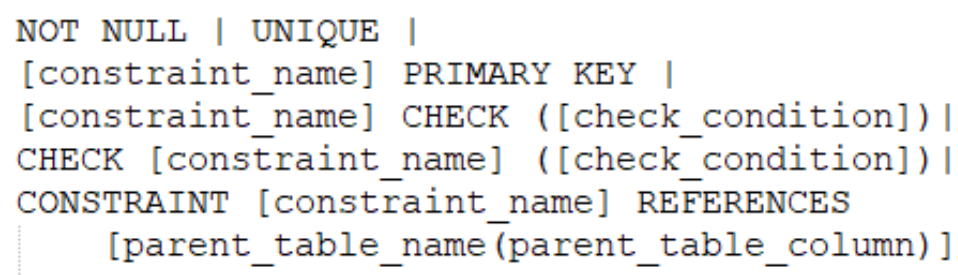

\section{Gambar 14. Pola DSL untuk column constraint}

Sedangkan pola umum penulisan table constraint pada tabel basis data dapat dilihat pada Gambar 15.

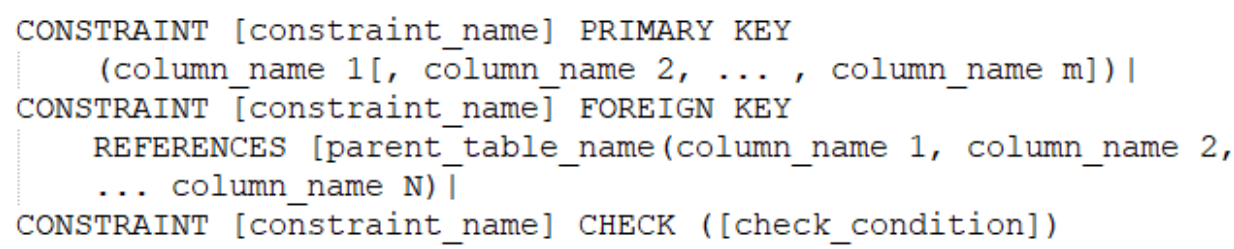

\section{Gambar 15. Pola DSL untuk table constraint}

Berdasarkan DSL yang telah disusun, dikembangkanlah grammaryang akan digunakan untuk mengartikan DDL yang menjadi input dari kakas generator data. Sebagian dari grammar tersebut dapat dilihat pada Gambar 16. Grammartersebut dikembangkan dengan ANTLR 4.7.1 dan Eclipse 2018-09 (For Java Developers) IDE. Grammar tersebut akan memerlukan penyesuaian untuk masing-masing DBMS jika DBMS tersebut menggunakan sintaks yang berbeda.

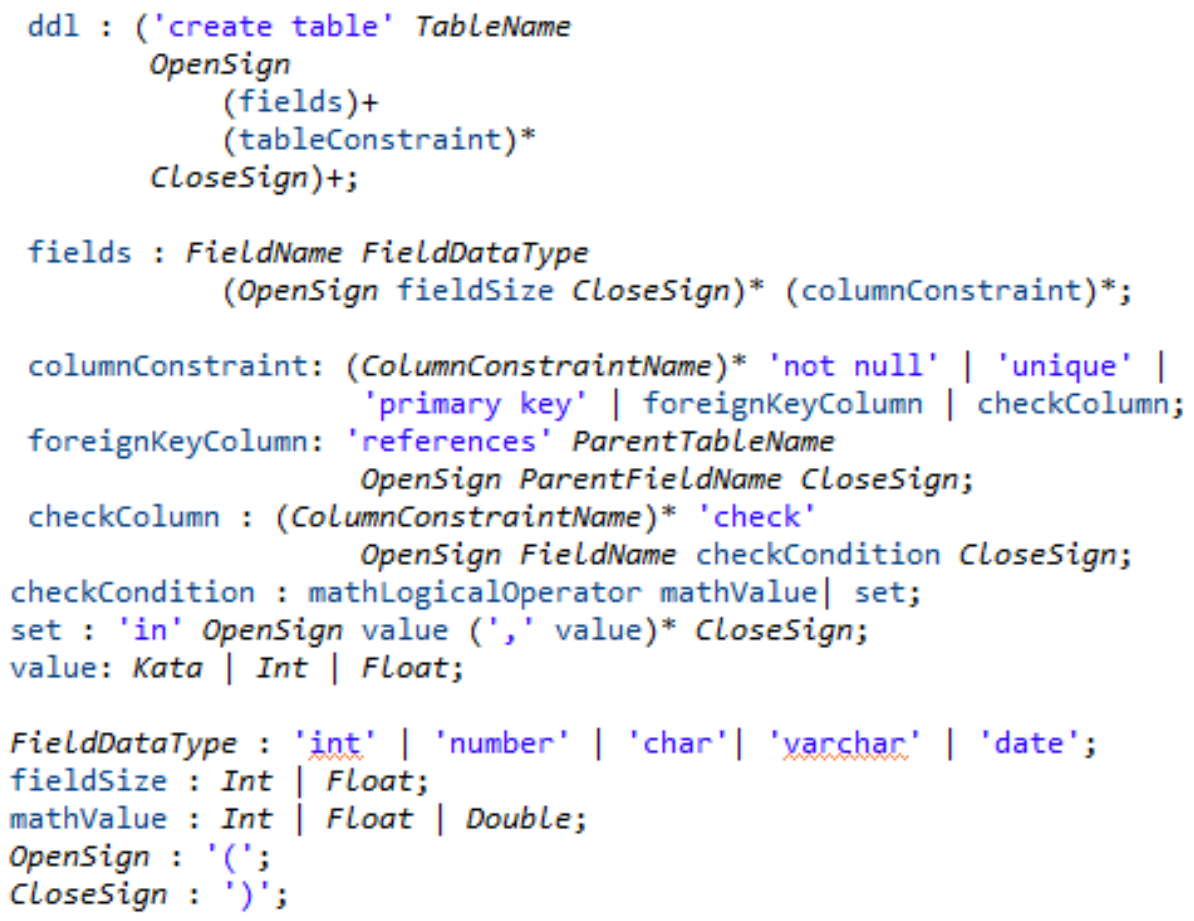

Gambar 16. Sebagian dari grammar data generator 
Beberapa hal yang perlu dikembangkan dalam perangkat lunak data generator adalah sebagai berikut:

1. Struktur data yang dapat digunakan untuk mencatat relasi antar tabel basis data. Relasi tersebut didapatkan dari DDL yang menjadi input kakas.

2. Penambahan tipe data yang saat ini belum ditangani, misalnya binary object.

3. Diperlukan data yang dapat digunakan sebagai data acak untuk data dummy, misalnya data nama orang, nama negara, nama kota, dan lain-lain.

\section{KESIMPULAN DAN SARAN}

Dalam penelitian ini, DSL yang didasarkan pada DDL basis data telah dianalisis dan dirancang. Grammar yang dapat digunakan untuk melakukan parsing DDL yang menjadi input untuk kakas generator data pun telah dikembangkan. Karena adanya perbedaan sintaks dan tipe data yang terdapat pada masing-masing DBMS, menyebabkan perlunya modifikasi pada grammar basis data jika grammar tersebut akan dikembangkan untuk DBMS lain.

Pada penelitian berikutnya, dapat dikembangkan kakas generator data yang memanfaatkan grammar yang telah tersedia. Grammar yang telah dikembangkan hanya dapat digunakan untuk relasi antar tabel yang dituliskan dengan berurutan, yaitu penulisan parent table sebelum child table. Dalam penelitian berikutnya dapat dikembangkan metode untuk menangkap relasi antar tabel walau penulisan pada DDL-nya tidak berurutan.

\section{DAFTAR RUJUKAN}

Fowler, M., \& Parsons, R. (2010). Domain Specific Languages. Addison-Wesley Professional. Parr, T. (2012). The Definitive ANTLR 4 Reference. The Pragmatic Programmers, LLC.

Silberschatz, A., Korth, H., \& Sudarshan, S. (2011). Database System Concepts (Vol. 6th edition). McGraw-Hill.

Natali, V., \& Liem, I. (2015). Automated data consistency checking using SBVR: Case study: Academic data in a University. 2015 International Conference on Data and Software Engineering (ICoDSE). Yogyakarta, Indonesia: IEEE.

Feuto, P., Cardey, S., \& Gree, P. (2013). Domain Specific Language Based on the SBVR Standard for Expressing Business Rules. Enterprise Distributed Object Computing Conference Workshops (EDOCW). Vancouver, BC, Canada: IEEE.

Marinos, A., \& Krause, P. (2009). An SBVR Framework for RESTful Web Applications. Rule Interchange and Applications, RuleML (hal. 144-158). Springer Berlin Heidelberg.

Moschoyiannis, S., Marinos, A., \& Krause, P. (2010). Generating SQL Queries from SBVR Rules. Semantic Web Rules, RuleML (hal. 128-143). Springer, Berlin, Heidelberg. 
Center, O. (2018, November 3). Database Administrator's Guide. Diambil kembali dari https://docs.oracle.com/cd/B28359_01/server.111/b28310/tables003.htm\#ADMIN110 04

Furuyama, Y. (2018, November 1). Data-Generator-FromDDL-0.06. Diambil kembali dari https://metacpan.org/pod/datagen_from_ddl

Generatedata.com versi 3.2.8. (2018, November 1). Diambil kembali dari http://www.generatedata.com

LLC, M. (2018, November 11). Mockaroo Realistic Data Generator. Diambil kembali dari https://www.mockaroo.com/

MySQLTutorial. (2018, November 3). MySQL Primary Key. Diambil kembali dari http://www.mysqltutorial.org/mysql-primary-key/ 